\title{
EVIDENCE FOR EXISTENCE OF MOLECULAR STEMNESS MARKERS IN PORCINE OVARIAN FOLLICULAR GRANULOSA CELLS
}

Katarzyna Stefańska ${ }^{1}$, Rafał Sibiak ${ }^{1}$, Greg Hutchings², Claudia Dompe ${ }^{2}$, Lisa Moncrieff ${ }^{2}$, Krzysztof Janowicz ${ }^{2}$, Michal Jeseta ${ }^{3}$, Bartosz Kempisty ${ }^{1,3,4}$, Marie Machatkova5 ${ }^{5}$ Paul Mozdziak ${ }^{6}$

\begin{abstract}
Granulosa cells (GCs) are important component of the follicle, a principal functional unit of the ovary. They undergo highly dynamic changes during folliculogenesis and play a vital role in oocyte's maturation. Recently, it has been shown that GCs also exhibit stem cell properties, since they express OCT-4, Nanog, Sox-2, which are markers of pluripotency, as well as several mesenchymal stem cell markers, such as CD29, CD44, CD90, CD105, CD117 or CD166. In addition, GCs are able to differentiate towards neurogenic, chondrogenic and osteogenic lineages. Since the use of embryonic stem cells in regenerative medicine is burdened with ethical concerns and the risk of immune rejection or teratoma formation, adult stem cells are emerging as a promising alternative. GCs especially seem to provide a promising source of stem cells, since they are easily obtainable during assisted reproduction techniques. In order to better understand the genetic changes taking place in proliferating granulosa cells cultured in vitro, we isolated GCs from 40 prepubertal gilts and cultured them in vitro for $168 \mathrm{~h}$. After 24, 48, 72, 96, 120, 144 and $168 \mathrm{~h}$ of cultivation the total RNA was extracted, reverse transcription was conducted and RT-qPCR reaction was performed. We observed that CD44, CD90 and IGF1 were upregulated after the cultivation, whereas CD105 and LIF were downregulated. Collectively, our results confirm stemness potential of porcine GCs and provide an insight into the transcriptome changes during in vitro cultivation.
\end{abstract}

Running title: Molecular stemness markers in porcine granulosa cells

Keywords: pig, granulosa cells, in vitro culture, RT-qPCR

\footnotetext{
${ }^{1}$ Department of Histology and Embryology, Poznan University of Medical Sciences, Poznań, Poland

${ }^{2}$ School of Medicine, Medical Sciences and Nutrition, University of Aberdeen, Aberdeen, United Kingdom

${ }^{3}$ Department of Obstetrics and Gynecology, University Hospital and Masaryk University, Brno, Czech Republic

${ }^{4}$ Department of Anatomy, Poznan University of Medical Sciences, Poznań, Poland

${ }^{5}$ Veterinary Research Institute, Brno, Czech Republic

${ }^{6}$ Physiology Graduate Program, North Carolina State University, Raleigh, NC, USA

* Correspondence: bkempisty@ump.edu.pl

Full list of author information is available at the end of article
} 


\section{Introduction}

The follicle is the principal functional unit of the ovary and mammalian folliculogenesis begins during fetal life. In pigs, the number of follicles at the moment of birth reaches 500000 , however it decreases to 80000 until puberty. The primordial follicles are formed at day 75 of gestation and comprise of a single layer of flattened granulosa cells (GCs), which surround the oocyte arrested in prophase-1 of meiosis [1]. Further follicular development occurs after puberty, when primordial follicles develop into primary follicles and granulosa cells become cuboidal. Then the secondary follicles are formed, when granulosa cells proliferate and form multiple layers surrounding the oocyte. The fully developed antral follicles are composed of three compartments (a thecal layer with a vascular network, a granulosa cells layer and an oocyte) and in most cases undergo atresia, however few are selected for ovulation [2-4].

Granulosa cells undergo highly dynamic changes during folliculogenesis and play vital role in oocyte's maturation, since they remain in close contact with the female gamete. The communication between the oocyte and somatic cells is bi-directional and occurs via gap junctions and paracrine signaling. The female gamete is involved in regulation of folliculogenesis, since it secretes oocyte secreted factors (OSF), which influence follicular cells' proliferation and differentiation [5], whereas the granulosa cells support the oocyte's growth and development, as well as regulate global transcriptional activity in its genome [6].

Apart from above described granulosa cells role in oogenesis, it has been shown that they also exhibit stem cell properties, which was first indicated by Kossowska-Tomaszczuk et al. [7]. In this study, the granulosa cells were extracted from the follicular fluid obtained from patients undergoing controlled ovarian hyperstimulation. Reverse transcriptase-PCR revealed expression of a pluripotency marker in luteinizing GCs, namely OCT-4. Moreover, the presence of several mesenchymal stem cell markers (such as CD29, CD44, CD90, CD105, CD117 or CD166) in isolated GCs has been confirmed as well. The multipotency of GCs has also been assessed by their differentiation into neurons, chondrocytes and osteoblasts in vitro [7]. On the contrary, the study conducted by Mattioli et al. revealed the lack of OCT-4 expression in GCs isolated from pigs, however the presence of other stemness markers, namely Nanog, Sox- 2 and TERT has been confirmed. The in vitro expansion of cells did not influence these markers' expression and their osteogenic differentiation potential has been demonstrated both in vitro and in vivo [8].

The stem cells have been a major focus of regenerative medicine in recent years. However, embryonic stem cells (ESCs) utilization involves embryos destruction and may cause teratoma formation or immune rejection after transplant [9], therefore the adult stem cells are emerging as a promising alternative. Granulosa cells seem to provide a promising source of stem cells, particularly since they are present in follicular fluid collected during assisted reproductive techniques, thus are easily obtainable. Further understanding transcriptional changes in proliferating GCs may be helpful for their utilization in cellular therapies, especially those targeted at female infertility [10]. Therefore, the aim of this study was to examine transcriptional changes in porcine GCs during $168 \mathrm{~h}$ in vitro culture with the use of RT-qPCR, with a particular focus on their stemness markers expression.

\section{Material and Methods \\ Animals}

A total of 40 pubertal crossbred Landrace gilts with a mean age of 155 days and a mean weight of $100 \mathrm{~kg}$ were used for this study. All animals were bred on a local commercial farm and housed under identical conditions. The experiments were approved by the Local Ethics Committee.

\section{Collection of porcine ovaries and in vitro cultivation of porcine granulosa cells (GCs)}

Immediately after the slaughter porcine ovaries were collected and placed at prewarmed $0.9 \%$ $\mathrm{NaCl}$. Within 40 minutes they were transported to the laboratory and transferred to 5\% fetal bovine serum (FBS; Sigma-Aldrich Co., St. Louis, MO, USA) in PBS. Then the follicular fluid was collected from single large follicles $(>5 \mathrm{~mm})$ with the use of a $20 \mathrm{G}$ needle to obtain granulosa cells. The follicular fluid was then filtered through $40 \mu \mathrm{m}$ cell strainer, to remove cumulus-oocyte complexes (COCs), and centrifuged at $200 \times \mathrm{g}$ for $10 \mathrm{~min}$ at RT. The supernatant was discarded and GCs were washed twice with culture medium, by centrifugation at $200 \times \mathrm{g}$ for $10 \mathrm{~min}$ at RT. Medium consisted of Dulbecco's Modified Eagle's Medium (DMEM/F12, Sigma-Aldrich, USA), $2 \%$ fetal calf serum FCS (PAA, Austria), $10 \mathrm{mg} / \mathrm{mL}$ ascorbic acid (Sigma-Aldrich, USA), $0.05 \mu \mathrm{M}$ dexamethasone (Sigma-Aldrich, USA), $200 \mathrm{mM} \mathrm{L-glu-}$ tamine (Invitrogen, USA), $10 \mathrm{mg} / \mathrm{mL}$ gentamicin (Invitrogen, USA), 10,000 units/mL penicillin, and $10,000 \mu \mathrm{g} / \mathrm{mL}$ streptomycin (Invitrogen, USA). Cells were cultivated at $38.5^{\circ} \mathrm{C}$ under aerobic conditions $\left(5 \% \mathrm{CO}_{2}\right)$ for $168 \mathrm{~h}$.

\section{Real-Time Quantitative Polymerase Chain Reaction (RT-qPCR) Analysis}

Total RNA was isolated from GCs after 24, 48, 72, $96,120,144$, and $168 \mathrm{~h}$ of culture with the use of RNeasy mini column from Qiagen $\mathrm{GmbH}$ (Hilden, Germany). The RNA samples were resuspended in $20 \mu \mathrm{L}$ of RNase-free water and stored in liquid nitrogen. Before RT-qPCR the RNA samples were sub- 
jected to treatment with DNase I and reverse transcribed (RT) into cDNA. $2 \mu \mathrm{L}$ of cDNA solution was added to $18 \mu \mathrm{L}$ of a detection dye QuantiTect巴 SYBR Green PCR (Master Mix Qiagen GmbH, Hilden, Germany) and primers for amplification. One RNA sample of each preparation was processed without the RT-reaction to provide a negative control for subsequent PCR. RT-qPCR was conducted using a LightCycler RT-qPCR detection system (Roche Diagnostics $\mathrm{GmbH}$, Mannheim, Germany) and target cDNA was quantified using the relative quantification method.

\section{Ethical approval}

The research related to animal use has been complied with all the relevant national regulations and instructional policies for the care and use of animals. Bioethical Committee approval no. 83/2012/DNT.

\section{Results}

We assessed the relative abundance of LIF, IGF1, CD44, CD90 and CD105 mRNA in equal time intervals - after 48, 72, 96, 120, 144 and $168 \mathrm{~h}$ in reference to $24 \mathrm{~h}$ of GCs in vitro cultivation with the use of RT-qPCR assay. The results are presented in figure 1; the relative changes are expressed in a commonly used logarithmic ratio fold change (FC) scale (the logarithm to base 2 is used, which means that an increase of a quantity by $100 \%$, i.e. 2 -fold, is represented by $1-\mathrm{FC}=2^{1}$ ).
We observed that in case of CD44, CD90 and IGF1 proteins the expression in GCs was elevated during all examined time periods, as compared to the expression observed after $24 \mathrm{~h}$ culture. On the other hand, the expression of CD105 and LIF was decreased.

The CD90 expression level was the highest amongst the examined proteins and rose gradually during the cultivation, reaching the highest level of the fold change of almost $2^{8}$ (with respect to the reference $24 \mathrm{~h}$ time interval) at $168 \mathrm{~h}$. The only exception was at the time of $96 \mathrm{~h}$ of cultivation, when its expression was not observed to increase as compared to the previously tested time period, namely $72 \mathrm{~h}$ of cultivation.

The next protein that exhibited the highest change in expression was IGF1. The maximum fold change in expression, of almost $2^{7}$, was reached after $120 \mathrm{~h}$. At later periods the expression tended to decrease, down to the approximate fold change value of below $2^{3}$; this means a 16 -fold decrease with respect to the maximum value.

Finally, for the last protein exhibiting the increase of expression, i.e. CD44, the increase was very moderate. The behavior was rather irregular, with two maxima - nearly $2^{2}$ (ca. 3 -fold change) after $72 \mathrm{~h}$ of cultivation and above $2^{2}$ (ca. 5 -fold change) after the longest period examined, i.e. $168 \mathrm{~h}$.

The other two proteins investigated suffered a moderate decrease of expression, down to ca. $2^{-2}$.

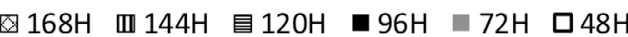

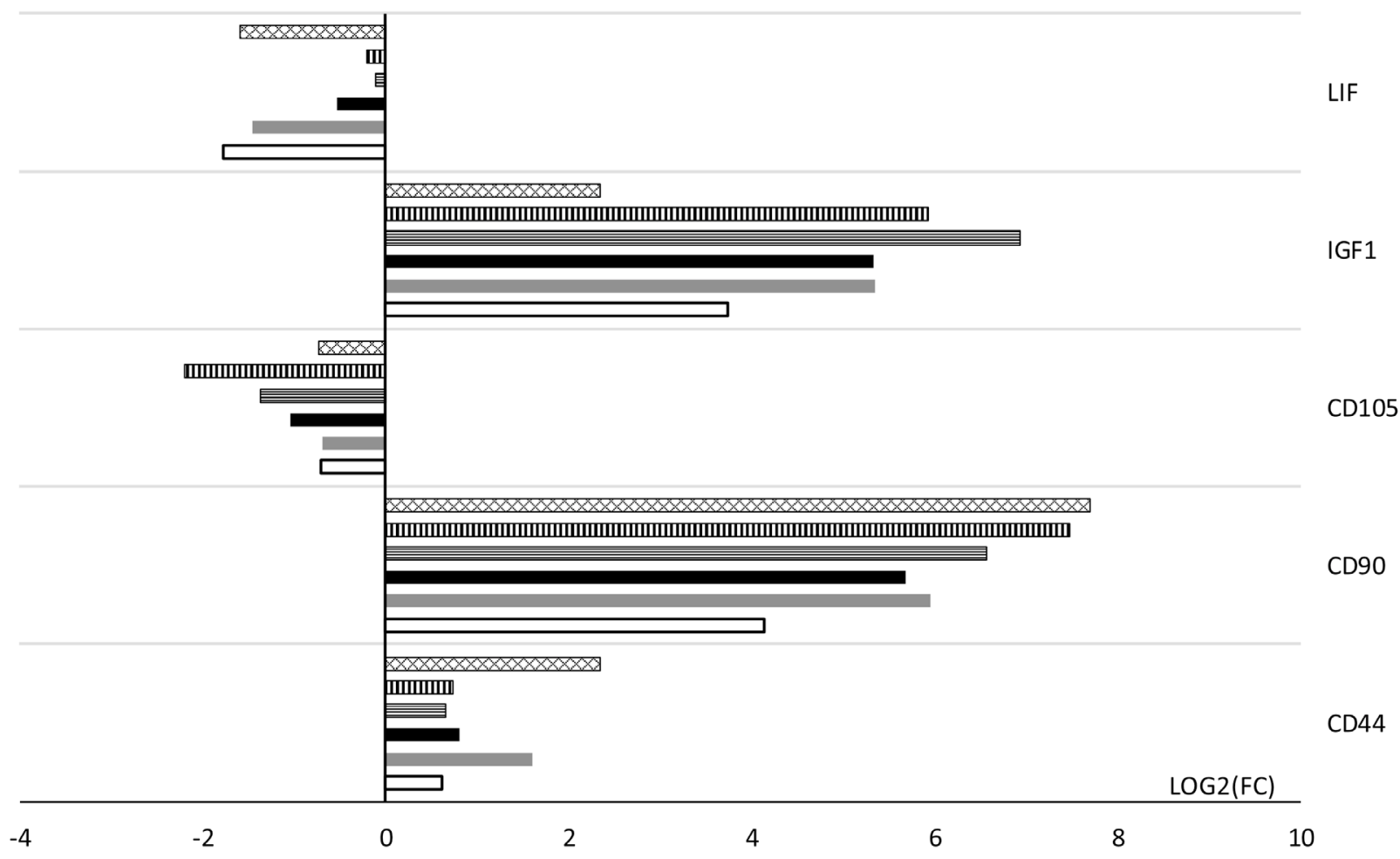

FIGURE 1 Expression of LIF, IGF1, CD44, CD90 and CD105 mRNA in granulosa cells (GCs) after various periods of in vitro cultivation; the results are expressed in logarithmic fold change scale, with the reference time interval of $24 \mathrm{~h}$ 
For CD105 the decrease in expression first proceeded approximately monotonically, since a maximum decrease was observed after $144 \mathrm{~h}$. Later the expression seemed to recover, roughly to the level observed after the initial intervals of $48 \mathrm{~h}$ and $72 \mathrm{~h}$ of cultivation. On the contrary, the behavior of the LIF expression was not regular. The first considerable decrease of expression was noted already after $48 \mathrm{~h}$, then the expression increased again, almost to the value observed after the reference interval of 24 $\mathrm{h}$, but finally an abrupt decrease after the last time span examined (168 h) was noted.

\section{Discussion}

In order to better understand the genetic changes taking place in proliferating granulosa cells cultured in vitro, we examined changes in transcript levels in porcine GCs during specific time periods, namely 48, $72,96,120,144$ and $168 \mathrm{~h}$ of cultivation. We focused on stemness markers expression, such as CD44, CD90 and CD105, as well as on IGF1 and LIF.

Amongst aforementioned genes, the CD44, CD90 and IGF1 were upregulated after in vitro cultivation. The most significant change in expression level was observed in case of CD90, which abundance gradually increased in GCs during tested time periods, reaching the highest level in $168 \mathrm{~h}$ of cultivation. CD90, also called THY1, was initially described in mice as a cell surface glycoprotein characteristic to $\mathrm{T}$ cells, however it is also present in thymocytes and neurons and is thought to be involved in cell-cell interactions [11]. Apart from that, CD90 is included in the list of antigens that mesenchymal stem cells must possess, according to the International Society for Cellular Therapy, therefore is considered a stemness marker [12]. Its presence has already been demonstrated in human granulosa cells by Kossowska-Tomaszczuk et al. [7] and Dzafic et al. [13] among others. Additionally, CD90 is thought to control cell differentiation in various tissues and its release from vascular pericytes in the ovaries has been linked with follicular differentiation. Indeed, the study conducted by Bukovský revealed that in follicles entering atresia CD90 is strongly released among thecal cells, which results in their high differentiation. On the contrary, in the same study granulosa cells displayed low differentiation, which was associated with lack of CD90 release amongst them [14]. We, on the other hand, report significant increase in CD90 expression in porcine GCs during $168 \mathrm{~h}$ in vitro cultivation. Considering previous reports by other investigators, our results may indicate that not only do porcine GCs possess stem cell properties to a certain degree, but also differentiate more intensely in a response to prolonged in vitro culture.

Another upregulated protein in our study was IGF1, however it reached the highest level of expression at $120 \mathrm{~h}$ of in vitro culture and declined afterwards. IGF1 (Insulin-like growth factor 1) is involved in growth and developmental processes in mammals and mediates the effects that growth hormone exerts. IGF1 complete amino acid sequence has been determined by Rinderknecht et al. and its homology to proinsulin has been indicated [15]. Although IGF1 is widely distributed throughout the mammalian organism, the liver was found to be the major site of its synthesis $[16,17]$. In regards of mammalian reproduction, the expression of IGF1 has been described by Oliver et al. in rat GCs of developing preantral and antral follicles [18] and this expression pattern has been observed in murine ovaries by Adashi et al. as well [19]. Since it is not present in atretic follicles or corpora lutea, an assumption has been made that IGF1 is expressed in mitotically active GCs and promotes their replication via an autocrine-paracrine mechanism [20], especially since $I g f$ null mice are infertile and their follicular development is arrested [21]. Additionally, the study conducted by Ogo et al. indicates that Igf1 mRNA expression is regulated by nuclear receptors ER $\alpha$ and ER $\beta$ and that IGF1 enhances the estrogen-induced proliferation of GCs [22]. Since we observed increasing expression of IGF1 until $120 \mathrm{~h}$ of porcine GCs in vitro culture, we hypothesize that after that time the IGF1-induced proliferation of GCs decreases.

The last of the upregulated genes in our study was CD44, which reached the highest level in $168 \mathrm{~h}$ of in vitro cultivation, similarly to CD90. Before that, its expression remained on relatively the same level, with the exception of $72 \mathrm{~h}$, when it was increased. CD44 is a cell membrane glycoprotein thought to be involved in cell attachment to extracellular matrix components, such as hyaluronate, as well as in lymphocyte activation and lymph node homing [23]. Hyaluronic acid causes cell aggregation in many types of cells, stimulates cell proliferation, migration and adhesion, as well as preventing apoptosis in cumulus and granulosa cells in a CD44-dependent manner $[24,25]$. Another ligand for CD44 is osteopontin and such interaction results in cellular chemotaxis induction, but not homotypic aggregation [26]. Apart from that, CD44 is considered a mesenchymal lineage marker and its presence in human GCs has already been described in a previously mentioned study conducted by Kossowska-Tomaszczuk et al. [7] and by Ohta et al., who suggested that CD44 plays important role in oocyte maturation, since its expression is higher in GCs of mature COCs compared to the immature ones [24]. The abundance of CD44 in porcine GCs has already been confirmed as well, and the parallel relation between the amount of hyaluronic acid and CD44 expression has been indicated [27]. Since the study conducted by Chavoshinejad et al. revealed that IGF1, combined with other factors such as oestradiol, gonadotropins or insulin, stimulated CD44 expression in ovine GCs [28], we conclude that 
this may be the case in our study, as we observed upregulation of both of these genes.

Amongst tested genes, CD105 and LIF were downregulated in GCs after in vitro culture. CD105, also called endoglin, is a membrane glycoprotein highly expressed by vascular endothelial cells. It is a component of the transforming growth factor-beta (TGFB) receptor complex and binds TGFB1 with high affinity [29]. Additionally, the International Society for Cellular Therapy included CD105 in the list of antigens that cells must possess in order to be designated mesenchymal stem cells [12]. CD105 null mice die by embryonic day 11.5 due to failure of end othelial remodeling [30], however, apart from playing an undoubtable role in vasculature development, endoglin is also involved in GCs function, since it is expressed by this type of cells [7,10,31]. It is generally accepted that follicle development is dependent on the establishment and continual remodeling of a complex vascular system, and was suggested that GCs may behave as endothelial cells and contribute to follicular angiogenesis [32]. Indeed, the study on porcine GCs conducted by Basini et al. revealed that these cells express several endothelial markers, including CD105, and that this expression seems to be more pronounced in cells cultured in specific endothelial cell culture medium (EBM-2) [32]. We however observed gradual decrease of CD105 levels during porcine GCs in vitro culture, reaching the lowest level at $144 \mathrm{~h}$, therefore it seems that in our culture conditions GCs lose their angiogenic potential. It is also possible, that a longer in vitro cultivation would result in restoration of their endothelial-like properties, since the expression of CD105 was significantly higher in $168 \mathrm{~h}$ of culture.

LIF (Leukemia-inhibitory factor) is a pleiotropic cytokine playing a crucial role in an embryo implantation in mice, since it is highly produced by endometrium and the trophoblast, while cytotrophoblast cells express its receptor [33]. Moreover, LIF is responsible for signal integration into mouse embryonic stem cells for their self-renewal and pluripotency maintenance [34], as well as for regulation of microvessel density by modulating oxygen-dependent VEGF expression in mice [35]. Leukemia-inhibitory factor has also been found to be expressed in human; both fetal and adult ovaries, suggesting its role in primordial follicles growth initiation [36]. Such notion has been confirmed by Nilsson et al., who observed that LIF treatment increases the primordial to primary rat follicle transition, possibly due to its interaction with Kit ligand [37]. In regards of granulosa cells, Kossowska-Tomaszczuk et al. demonstrated that the presence of LIF in culture medium promotes multipotent GCs survival in vitro. Such cultured cells exhibited reduced expression of neurogenic, chondrogenic or osteogenic differentiation markers, comparing to those cultured in medium without the addition of LIF. Therefore, culture medium supplemented with LIF allowed the selection of less differentiated GCs [7]. Since LIF is thought to maintain stemness potential of cells, its downregulation in our study may indicate that porcine GCs start to differentiate in $168 \mathrm{~h}$ of in vitro cultivation. This assumption is consistent with an increased CD90 expression, which also suggests these cells differentiation.

To summarise, our results confirm stemness potential of porcine GCs, since they express markers such as CD90, CD44 or CD105. The downregulation of CD105 may indicate that their intrinsic endothelial potential is reduced after in vitro cultivation and an increased CD90 and decreased LIF level suggests that these cells start to differentiate. Additionally, we observed upregulation of IGF1 and CD44. Since both of these proteins are thought to cooperate in regulation of cell proliferation, we conclude that this may be the case in our study, especially because CD44 has been proven to prevent GCs from apoptosis. Our results provide an insight into the transcriptome changes in porcine GCs during in vitro cultivation, however it is important to remember that these changes may not be an exact reflection of processes taking place in physiological conditions.

\section{Acknowledgements}

This publication and its results are an outcome of a cooperation between Poznan University of Medical Sciences (Poznań, Poland) and Polish Ministry of Science and Higher Education, with Institute of Advanced Sciences Sp. z o.o. (Poznań, Poland), as a part of the "Professional PhD" programme.

\section{Corresponding author}

Bartosz Kempisty, Department of Anatomy, Poznan University of Medical Sciences, 6 Święcickiego St., 60-781 Poznań, Poland, Tel./ Fax: +48 61 8546565, e-mail: bkempisty@ump.edu.pl.

\section{Conflict of interest statement}

The authors declare they have no conflict of interest.

\section{References}

1. Błocińska R. Folikulogeneza i steroidogeneza jajnikowa u świń. Zesz Nauk Tow Doktorantów Uniw Jagiellońskiego. 2010.

2. MATSUDA F, INOUE N, MANABE N, OHKURA S. Follicular Growth and Atresia in Mammalian Ovaries: Regulation by Survival and Death of Granulosa Cells. J Reprod Dev. 2012;58:44-50; DOI:10.1262/ jrd.2011-012.

3. Gougeon A. Regulation of ovarian follicular development in primates: facts and hypotheses. Endocr Rev. 1996; DOI:10.1210/er.17.2.121.

4. Uyar A, Torrealday S, Seli E. Cumulus and granulosa cell markers of oocyte and embryo quality. Fertil Steril. 2013;99:979-97; DOI:10.1016/j.fertnstert.2013.01.129.

5. Gilchrist RB, Lane M, Thompson JG. Oocyte-secreted factors: regulators of cumulus cell function and oocyte quality. Hum Reprod Update. 2008;14:159-77; DOI:10.1093/humupd/dmm040.

6. Hamel M, Dufort I, Robert C, Leveille M-C, Leader A, Sirard M-A. Genomic assessment of follicular marker genes as pregnancy predictors for human IVF. Mol Hum Reprod. 2010;16:87-96; DOI:10.1093/molehr/ gap079.

7. Kossowska-Tomaszczuk K, De Geyter C, De Geyter M, Martin I, Holzgreve W, Scherberich A, Zhang H. The Multipotency of Luteinizing Granulosa Cells Collected from Mature Ovarian Follicles. Stem Cells. 2009;27:2109; DOI:10.1634/stemcells.2008-0233.

8. Mattioli M, Gloria A, Turriani M, Berardinelli P, Russo V, Nardinocchi D, Curini V, Baratta M, Martignani E, Barboni B. Osteo-regenerative potential of ovarian granulosa cells: An in vitro and in vivo study. Theriogenology. 2012;77:1425-37; DOI:10.1016/j.theriogenology.2011.11.008. 
9. Doğan A. Embryonic Stem Cells in Development and Regenerative Medicine, Springer, Cham; 2018;1-15; DOI:10.1007/5584_2018_175.

10. Dzafic E, Stimpfel M, Virant-Klun I. Plasticity of granulosa cells: on the crossroad of stemness and transdifferentiation potential. J Assist Reprod Genet. 2013;30:1255-61; DOI:10.1007/s10815-013-0068-0.

11. Raff MC. Surface antigenic markers for distinguishing T and B lymphocytes in mice. Transplant Rev. 1971;6:52-80; DOI:10.1111/j. 1600-065x.1971.tb00459.x.

12. Dominici M, Le Blanc K, Mueller I, Slaper-Cortenbach I, Marini F., Krause DS, Deans RJ, Keating A, Prockop DJ, Horwitz EM. Minimal criteria for defining multipotent mesenchymal stromal cells. The International Society for Cellular Therapy position statement. Cytotherapy. 2006;8:3157; DOI:10.1080/14653240600855905.

13. Dzafic E, Stimpfel M, Novakovic S, Cerkovnik P, Virant-Klun I. Expression of mesenchymal stem cells-related genes and plasticity of aspirated follicular cells obtained from infertile women. Biomed Res Int 2014;2014:508216; DOI:10.1155/2014/508216.

14. Bukovský A, Caudle MR, Keenan JA, Wimalasena J, Foster JS, Van Meter SE. Quantitative Evaluation of the Cell Cycle-Related Retinoblastoma Protein and Localization of Thy-1 Differentiation Protein and Macrophages during Follicular Development and Atresia, and in $\mathrm{Hu}-$ man Corpora Lutea1. Biol Reprod. 1995;52:776-92; DOI:10.1095/ biolreprod52.4.776.

15. Rinderknecht E, Humbel RE. The amino acid sequence of human insulin-like growth factor I and its structural homology with proinsulin. J Biol Chem. 1978;253:2769-76.

16. Mathews LS, Norstedt G, Palmiter RD. Regulation of insulin-like growth factor I gene expression by growth hormone. Proc Natl Acad Sci. 1986;83:9343-7; DOI:10.1073/pnas.83.24.9343.

17. Rotwein P. Two insulin-like growth factor I messenger RNAs are expressed in human liver. Proc Natl Acad Sci U S A. 1986;83:77-81; DOI:10.1073/pnas.83.1.77

18. Oliver Je, Aitman Tj, Powell Jf, Wilson Ca, Clayton Rn. Insulin-Like Growth Factor I Gene Expression in the Rat Ovary is Confined to the Granulosa Cells of Developing Follicles. Endocrinology. 1989;124:2671-9; DOI:10.1210/endo-124-6-2671.

19. Adashi EY, Resnick CE, Payne DW, Rosenfeld RG, Matsumoto T, Hunter MK, Gargosky SE, Zhou J, Bondy CA. The Mouse Intraovarian Insulin-Like Growth Factor I System: Departures from the Rat Paradigm*. Endocrinology. 1997;138:3881-90; DOI:10.1210/endo.138.9.5363.

20. Zhou J, Refuerzo J, Bondy C. Granulosa cell DNA synthesis is strictly correlated with the presence of insulin-like growth factor I and absence of c-fos/c-jun expression. Mol Endocrinol. 1995;9:924-31; DOI:10.1210/ mend.9.7.7476974

21. Kadakia R, Arraztoa JA, Bondy C, Zhou J. Granulosa cell proliferation is impaired in the Igf1 null ovary. Growth Horm IGF Res. 2001;11:220-4 DOI:10.1054/ghir.2001.0201.

22. Ogo Y, Taniuchi S, Ojima F, Hayashi S, Murakami I, Saito Y, Takeuchi S, Kudo T, Takahashi S. IGF-1 gene expression is differentially regulated by estrogen receptors $\alpha$ and $\beta$ in mouse endometrial stromal cells and ovarian granulosa cells. J Reprod Dev. 2014;60:216-23; DOI:10.1262/ jrd.2013-085.

23. Aruffo A, Stamenkovic I, Melnick M, Underhill CB, Seed B. CD44 is the principal cell surface receptor for hyaluronate. Cell. 1990;61:1303-13; DOI:10.1016/0092-8674(90)90694-a.

24. Ohta N, Saito H, Kuzumaki T, Takahashi T, Ito MM, Saito T, Nakahara K, Hiroi M. Expression of CD44 in human cumulus and mural granulosa cells of individual patients in in-vitro fertilization programmes. Mol Hum Reprod. 1999;5:22-8; DOI:10.1093/molehr/5.1.22.

25. Kaneko T, Saito H, Toya M, Satio T, Nakahara K, Hiroi M. Hyaluronic acid inhibits apoptosis in granulosa cells via CD44. J Assist Reprod Genet. 2000;17:162-7; DOI:10.1023/a:1009470206468.

26. Weber GF, Ashkar S, Glimcher MJ, Cantor H. Receptor-Ligand Interaction Between CD44 and Osteopontin (Eta-1). Science. 1996;271:509-12; DOI:10.1126/science.271.5248.509.

27. Tunjung WAS, Yokoo M, Hoshino Y, Miyake Y, Kadowaki A, Sato E. Effect of hyaluronan to inhibit caspase activation in porcine granulosa cells. Biochem Biophys Res Commun. 2009;382:160-4; DOI:10.1016/j. bbrc.2009.02.163.

28. Chavoshinejad R, Marei WFA, Hartshorne GM, Fouladi-Nashta AA Localisation and endocrine control of hyaluronan synthase (HAS) 2 , HAS3 and CD44 expression in sheep granulosa cells. Reprod Fertil Dev. 2016;28:765; DOI:10.1071/RD14294.

29. Ríus C, Smith JD, Almendro N, Langa C, Botella LM, Marchuk DA, Vary $\mathrm{CP}$, Bernabéu C. Cloning of the promoter region of human endoglin, the target gene for hereditary hemorrhagic telangiectasia type 1. Blood. 1998;92:4677-90.
30. Li DY, Sorensen LK, Brooke BS, Urness LD, Davis EC, Taylor DG, Boak BB, Wendel DP. Defective Angiogenesis in Mice Lacking Endoglin. Science. 1999;284:1534-7; DOI:10.1126/science.284.5419.1534.

31. Ai A, Tang Z, Liu Y, Yu S, Li B, Huang H, Wang X, Cao Y, Zhang W. Characterization and identification of human immortalized granulosa cells derived from ovarian follicular fluid. Exp Ther Med. 2019;18:2167-77; DOI:10.3892/etm.2019.7802.

32. Basini G, Falasconi I, Bussolati S, Grolli S, Di Lecce R, Grasselli F. Swine Granulosa Cells Show Typical Endothelial Cell Characteristics. Reprod Sci. 2016; DOI:10.1177/1933719115612130.

33. Bamberger A-M, Jenatschke S, Schulte HM, Löning T, Bamberger CM. Leukemia Inhibitory Factor (LIF) Stimulates the Human HLA-G Promoter in JEG3 Choriocarcinoma Cells. J Clin Endocrinol Metab. 2000;85:39326; DOI:10.1210/jcem.85.10.6849.

34. Niwa H, Ogawa K, Shimosato D, Adachi K. A parallel circuit of LIF signalling pathways maintains pluripotency of mouse ES cells. Nature. 2009;460:118-22; DOI:10.1038/nature08113.

35. Kubota Y, Hirashima M, Kishi K, Stewart CL, Suda T. Leukemia inhibitory factor regulates microvessel density by modulating oxygen-dependent VEGF expression in mice. J Clin Invest. 2008;118:2393-403; DOI:10.1172/JCI34882.

36. Abir R, Fisch B, Jin S, Barnnet M, Freimann S, Van den Hurk R, Feldberg D, Nitke S, Krissi H, Ao A. Immunocytochemical detection and RT-PCR expression of leukaemia inhibitory factor and its receptor in human fetal and adult ovaries. Mol Hum Reprod. 2004;10:313-9; D0I:10.1093/ molehr/gah047.

37. Nilsson EE, Kezele P, Skinner MK. Leukemia inhibitory factor (LIF) promotes the primordial to primary follicle transition in rat ovaries. Mol Cell Endocrinol. 2002;188:65-73; DOI:10.1016/S0303-7207(01)00746-8. 